\title{
Exploring Inorganic Phosphate Solubilizing Trait of Halotolerant Rhizobacteria Isolated From Cuminum cyminum
}

\author{
Shah Rupal K ${ }^{1}$., Meenu Saraf* \\ ${ }^{1}$ Ph.D. Research Scholar \\ *Professor and Head of Department \\ Department of Microbiology and Biotechnology, \\ University School of Sciences, Gujarat University, Ahmedabad-380 009, India. \\ shahrupal1989@gmail.com sarafmeenu@gmail.com
}

\begin{abstract}
Phosphorus is an important macronutrient that is essential for plant growth and development. Inorganic phosphorus (P), which can make up to $70 \%$ of the total $\mathrm{P}$ content in soils, can exist in calcium-, aluminum- or ironcomplexed forms that are unavailable for plant use. As a result, mineral phosphorus, $\mathrm{P}_{2} \mathrm{O}_{5}$, is often used as a fertilizer to supplement the nutrient for crop growth. Soil microorganisms play a role in maintaining the ecological balance by active participation in nutrient cycles in nature. Phosphate Solubilizing Bacteria (PSB) as a phosphorus bio fertilizer improves soil fertility by solubilizing insoluble phosphate salts and increase crop production. This research aimed in isolation salt-tolerant or halotolerant PSB will facilitate the development of saline-alkali soil-based agriculture. The fastest growth was observed when the culturing temperature was $30^{\circ} \mathrm{C} \pm 2^{\circ} \mathrm{C}$ and the concentration of $\mathrm{NaCl}$ was $6 \%(\mathrm{w} / \mathrm{v})$. It was found that the isolates can survive at a concentration of $\mathrm{NaCl}$ up to $20 \%$. Halo zone formation and plate screening method was used for phosphate solubilization evaluation on Pikovskaya's agar medium, containing insoluble tri- calcium phosphate (TCP). Isolates showing highest Phosphate Solubilization Index (PSI) were selected for further study as qualitative as well as quantitative activities. The growth of the isolates was related with a significant decrease of $\mathrm{pH}$ of the medium which indicates the production of acids like acetic acid, formic acids etc. These isolates will be further identified by $16 \mathrm{~S}$ rRNA, their morphological and biochemical properties respectively.
\end{abstract}

Keywords: Phosphorus,PSB,NaCl,Phosphate.

\section{INTRODUCTION}

Phosphorus is an important plant nutrient next only to nitrogen.It is a master key element in crop production (Pierre, 1938). It is a component of key molecules such as nucleic acids, phospholipids and ATP.It stimulates the root growth at early stages of plant growth, helps in early maturity of crops and inadequate availability of it markedly reduces plant growth, reduces plant size and unusually deep green colouration. Plants acquire P from soil as phosphate anions. $\mathrm{P}$ is abundant in soils in both organic and inorganic forms, $\mathrm{P}$ deficiency is a serious concern for agriculture productivity and sustainability around the globe, Despite having rich total $\mathrm{P}$ contents, the available $\mathrm{P}$ in even most fertile soils are too low to meet most plants' demands due to precipitation with $\mathrm{Ca}^{2+}$ in alkaline soils (Rahmatullah et al.1994) and with $\mathrm{Al}^{3+}$ and $\mathrm{Fe}^{3+}$ oxides in acid soils (Plaxton and Carswell 1999; Raghothama 1999)
Since phosphorus content is quite low in saline soil so the application of phosphatic fertilizer is essential for better crop yield. However, P reacts very strongly with soil constituents, as a result only about $5-25 \%$ of applied $\mathrm{P}$ can be utilized by the plants while the remaining $75-95 \%$ of applied $\mathrm{P}$ is being rapidly fixed and transformed into insoluble forms unavailable to plants (Yin et al. 2015).More than $2 / 3$ of this fertilizer is rendered unavailable due to fixation in soil complex.They also causes surface and ground water pollution and various other deleterious effects.

Several reports indicated that various bacterial species have the ability to solubilize insoluble inorganic phosphate compounds like Tricalcium Phosphate (TCP),Dicalcium Phosphate(DCP), hydroxyapatite and Rock phosphate. Solubilization of insoluble $\mathrm{P}$ by microorganisms was reported by Pikovskaya (1948).These specific groups of soil microbes known as 


\section{International Journal of Research in Advent Technology, Vol.7, No.5, May 2019$$
\text { E-ISSN: 2321-9637 }
$$ \\ Available online at www.ijrat.org}

PSB(Phosphate Solubilizing Bacteria) which increase the availability of phosphates to plants, not only by mineralizing organic phosphorus compounds but also by rendering inorganic phosphorus compounds more available to them.(Gaur,1979). PSB vary in efficiency in solubilizing inorganic phosphate are known to render insoluble phosphate into a soluble form through the process of solubilization (inorganic $\mathrm{P}$ )/mineralization (organic P) by releasing low molecular mass organic acids, phosphatases or other complex agents (Duponnois et al. 2005). The concentration of iron ore, temperature, and $\mathrm{C}$ and $\mathrm{N}$ sources greatly influence the P-solubilizing potentials of these microbes. Among the various nutrients used by these microorganisms, ammonium salts has been found to be the best $\mathrm{N}$ source followed by asparagine, sodium nitrate, potassium nitrate, urea and calcium nitrate (Ahuja et al. 2007).The role of PSB is shown in Figure:1.

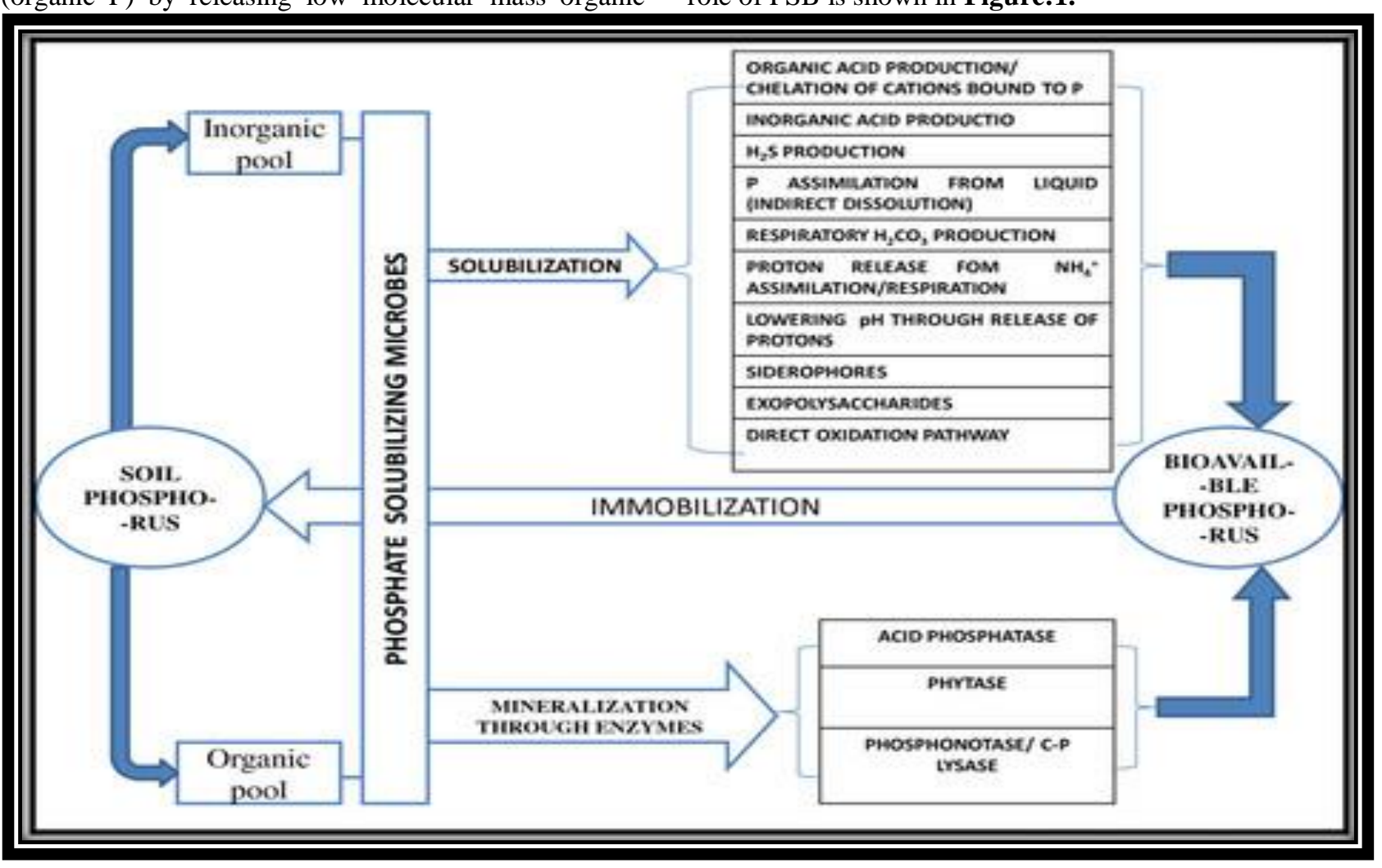

Figure: 1 Schematic representation of PSB mechanism in increasing soil phosphorus (Seema et al.2013)

Application of phosphate solubilizing microorganisms including bacteria, fungi and yeast to agriculture ecosystems have been considered as a low-cost and lowenergy management strategy to enhance the agronomic effectiveness and efficiency of both soluble and insoluble P fertilizers, especially insoluble RP (Biswas and Narayanasamy, 2006; Xiao et al. 2013; Abbasi et al. 2015; Bakhshandeh et al. 2015). PSB constitute 1-50\%. Moderately halotolerant bacteria are capable of growing at 4 to $20 \%(0.8$ to $3.4 \mathrm{M}) \mathrm{NaCl}$ concentration. These halotolerant bacteria are capable to solubilize phosphate in saline areas and make it available to plants in saline areas. They are the promising strategy to improve world food production without causing any environmental hazards.

\section{MATERIALS AND METHODS}

\subsection{Study sites and rhizospheric soil sampling}

3 different sites from Kachchh district, Gujarat,India were selected for sampling of soil in 2015. The air temperature of the sites varied between $25^{\circ} \mathrm{C}$ and $30^{\circ} \mathrm{C}$, soil temperature $20^{\circ} \mathrm{Cand} 25^{\circ} \mathrm{C}$. Before sampling, grass, forest litter or any other material on the soil surface were removed.Within each site, rhizospheric soil samples of Cuminum cyminum from $15 \mathrm{~cm}$ were collected by soil auger and mixed as one composite sample and stored at $4^{\circ} \mathrm{C}$ for isolation of PSB.A subsample of about $0.5 \mathrm{~kg}$ was air-dried and passed through 2-mm sieve and used for the determination of physical and chemical characteristics. The physicochemical parameter of the samples were 


\section{International Journal of Research in Advent Technology, Vol.7, No.5, May 2019 E-ISSN: 2321-9637 Available online at www.ijrat.org}

analysed at the sampling site (in situ) and in the microbiology laboratory (ex situ) using the physicochemical methods mentioned below.

The physical parameters includes:

1. $\mathrm{pH}$ by Ion Specific Electrode method

2. Electric Conductivity (Kalra and Maynard, 1991)

3. Salinity (Electrical salinity method)

4. Bulk density (Laboratory method for disturbed soil)

5. Soil texture (Laboratory method for disturbed soil)

6. Soil moisture by Gravimetric method 7. Redox potential by Potentiometric method

\subsection{Isolation of halotolerant rhizobacteria}

Composite Rhizospheric soil sample stored at $4^{\circ} \mathrm{C}$ was used for bacterial isolation.Rhizospheric bacteria were isolated by adding $1 \mathrm{~g}$ soil sample in $99 \mathrm{ml}$ sterile distilled water and kept the flask on shaking for $20 \mathrm{~min}$ to separate microorganisms completely from the soils, allowed to stand for 1 hour. Then the supernatant was used for serial dilution plating on nutrient agar plates having $\mathrm{NaCl}$ concentration of $6 \%$ The plates were incubated at $30 \pm 2^{\circ} \mathrm{C}$ till the appearance of bacterial colonies. Individual colonies were picked and streaked on nutrient agar plates for further purification. Morphological characteristics of colonies were recorded after $24 \mathrm{~h}$ of growth on nutrient agar plates at $30 \pm 2^{\circ} \mathrm{C}$. Bacterial colonies having different morphological characteristics were screened and 30 isolates were selected for evaluating their cell morphology The slides of screened strains were prepared to study Gram positive or negative characteristics by staining techniques(Murray et al. 1994).

\subsection{Culture Maintenance}

Bacterial cultures were maintained on nutrient agar slants having $6 \% \mathrm{NaCl}$ concentration as per in their respective plates and preserved at $4^{\circ} \mathrm{C}$ under refrigerator

\subsection{Phosphorus Solubilization Assay}

\section{A) Qualitative Assay}

Phosphorus solubilizing capacity of isolates on Pikovskaya's agar plate medium having bromophenol blue dye(Gupta et al,1992) and Nacl concentration upto $6 \%$.The potential of isolates to solubilize insoluble phosphates was examined on the Pikovskaya's medium (Pikovskaya 1948).Each bacterial culture in its isolated single colonial form was spot inoculated in the center of agar plates of Pikovskaya's media, containing tricalcium phosphate $\left[\mathrm{Ca}_{3}\left(\mathrm{PO}_{4}\right)_{2}\right]$ as insoluble phosphate source. The plates were incubated at $28 \pm 2^{\circ} \mathrm{C}$ for 6 days .Isolates capable of solubilizing insoluble phosphates will form halos.Using the diameter of clearing halozones, $\mathrm{P}$ solubilization index (PSI) was calculated by the formula mentioned below (Edi-Premono et al. 1996).

$$
\mathrm{PSI}=\frac{\text { colony diameter+halozone diameter }}{\text { colony diameter }}
$$

\section{Enrichment Method for Isolation}

$1 \mathrm{~g}$ of soil sample was added to $100 \mathrm{ml}$ Pikovskaya's broth containing flask and three successive transfers were made weekly intervals to enrich the medium.Then from the final flasks,PSBs were isolated by streaking a loopful of the culture on solid phosphate medium.The colonies showing halo zones were purified and preserved.

\section{B) Quantitative Assay}

Phosphorus solubilizing capacity of PSB was determined in $100 \mathrm{~mL}$ Pikovskaya's broth medium (liquidmedium) containing TCP insoluble $\left[\mathrm{Ca}_{3}\left(\mathrm{PO}_{4}\right)_{2}\right]$. The insoluble $\mathrm{P}$ source was added to $100 \mathrm{~mL}$ broth before sterilization.Then $1 \mathrm{ml}$ suspension of each bacterial culture was added to the broth under sterilized conditions.One control i.e. one without PSB or plant growth promoting rhizobacteria (PGPR) was also maintained. The PSB were allowed to grow for 21 days at $28 \pm 2^{\circ} \mathrm{C}$ on rotatory shaker.Growth medium $(5 \mathrm{ml})$ was withdrawn aseptically at 7 days interval from each flasks and centrifuged at 10,000rpm for $20 \mathrm{mins}$. The supernatant was analyzed for $\mathrm{P}_{2} \mathrm{O}_{5}$ content by Chlorostannous reduced molybdophosphoric acid blue method using Systronic 166 spectrophotometer (Gaur,1990). The $\mathrm{pH}$ of the supernatant was also checked by $\mathrm{pH}$ meter( and correlated with the results obtained on plates and in liquid medium.Standard graph was prepared using $\mathrm{KH}_{2} \mathrm{PO}_{4}(2-10 \mathrm{ppm} / \mathrm{ml})$ as standard reagent.Figure: 2 showing the protocol followed for isolation of phosphate solubilizer.. The isolates will be futher identified by $16 \mathrm{~S}$ r-RNA gene analysis. Further phylogenetic analysis will be used to confirm that these isolates were closely related to their respective strains through MEGA 7.0 software. 


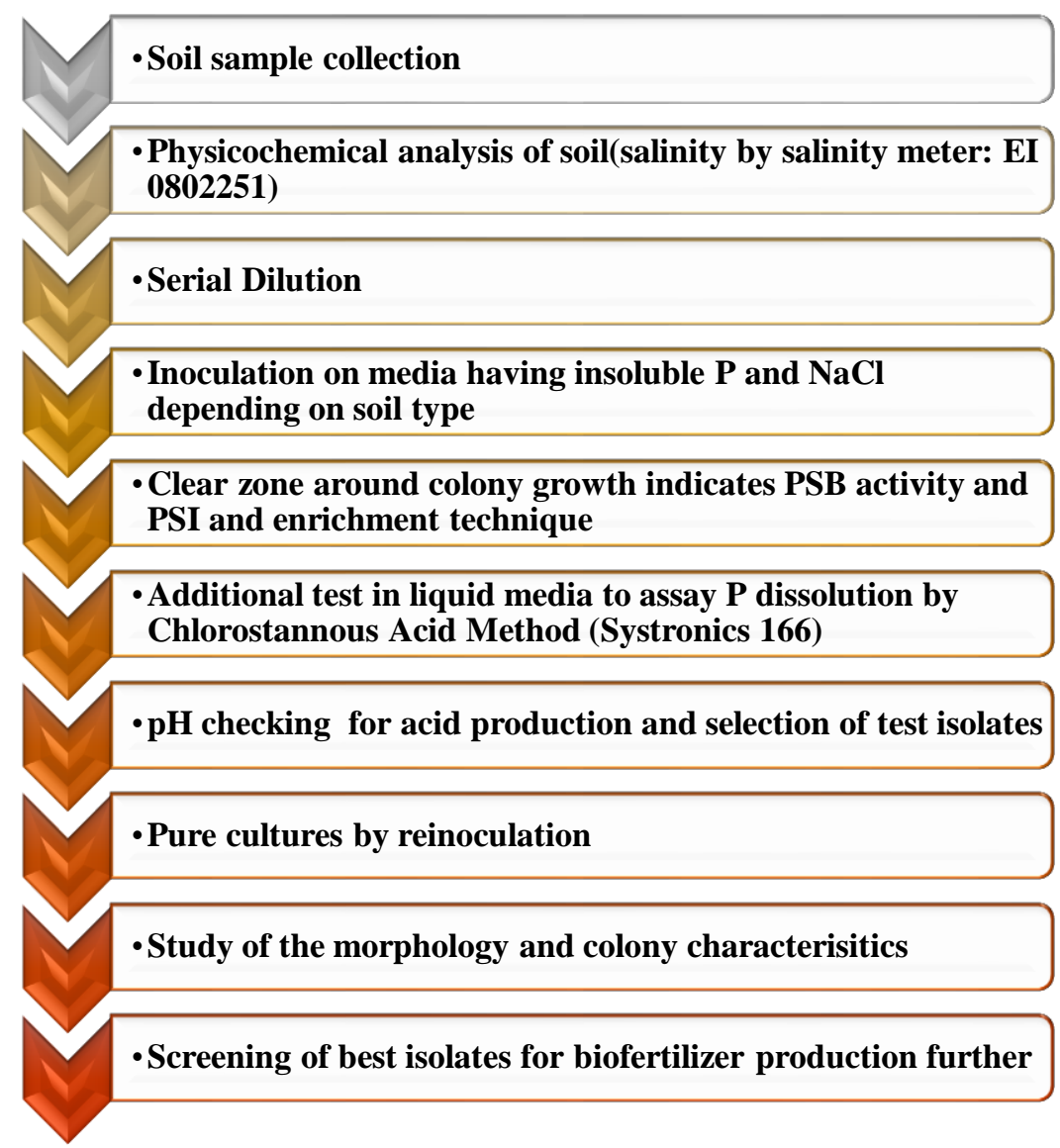

Figure:2 Protocol followed for isolation of phosphate solubilizer

\section{RESULTS AND DISCUSSION}

\subsection{Physical Characteristics of soil sample}

Physical characteristics of soil sample of cumin rhizosphere like colour,appearance,soil type,temperature(both internal and external were studied.The soil colour is brown with salt crystals and its texture was sandy to loamy. The outer temperature of the soil was $40^{\circ} \mathrm{C} \pm 2^{\circ} \mathrm{C}$ where as the internal temperature was $35^{\circ} \mathrm{C} \pm 2{ }^{\circ} \mathrm{C}$.

\subsection{Chemical Characteristics of soil sample}

Soil sample showed the higher value of $\mathrm{Cl}^{-}$, redox potential ,salinity and $\mathrm{Fe}$ content with highest TDS
values(Table 1).Higher value of redox potential reflects higher microbial activities in the soil.Highest Tds and ph showed that the soil was alkaline in nature.There was presence of other soluble salts also that helps in making the soil saline in nature. This indicated that soil is not suitable for the farming.Higher nitrogen content was found in the soil sample indicated that the soil have higher microbial counts and diversity.Zhou et al. 2002 suggested that the organic and inorganic content of soil is one of the most important key for driving the microbial community structure.

Table:1Physicochemical analysis of soil

\begin{tabular}{|c|c|c|c|}
\hline Sr. No. & Parameter & Unit & $\begin{array}{c}\text { Cumin } \\
\text { Soil }\end{array}$ \\
\hline 1 & $\mathrm{pH}$ & Direct & 8.6 \\
\hline 2 & Electric Conductivity & Milli.moh/cm & 0.60 \\
\hline 3 & $\operatorname{Org}-\mathrm{C}$ & In \% & 1.37 \\
\hline
\end{tabular}


Available online at www.ijrat.org

\begin{tabular}{clcc}
\hline 4 & Nitrogen & In $\%$ & 0.12 \\
5 & $\mathrm{Av} . \mathrm{P}$ & $\mathrm{ppm}$ & 3.62 \\
6 & $\mathrm{Av} . \mathrm{K}$ & $\mathrm{ppm}$ & 26 \\
7 & $\mathrm{Cu}$ & $\mathrm{ppm}$ & 1.82 \\
8 & $\mathrm{Zn}$ & $\mathrm{ppm}$ & 2.32 \\
9 & $\mathrm{Mn}$ & $\mathrm{ppm}$ & 5.94 \\
10 & $\mathrm{Fe}$ & $\mathrm{ppm}$ & 58.75 \\
11 & Boron & $\mathrm{ppm}$ & 1.34 \\
12 & Sulphur & $\mathrm{ppm}$ & 21.7 \\
13 & $\mathrm{Cl}$ & $\mathrm{mg} / \mathrm{K}$ & 300 \\
14 & TDS & & 250 \\
15 & $\mathrm{mV}$ & & 252 \\
16 & Salinity & $\mathrm{ppt}$ & 50 \\
17 & Bulk density & $\mathrm{mg} / \mathrm{m}^{3}$ & 1.33 \\
18 & Soil moisture & $\mathrm{In} \%$ & 12.60 \\
\hline
\end{tabular}

\subsection{Isolation of halotolerant rhizobacteria}

Isolates showing variations in their colony morphology were selected and purified by subculturing.Total 30 isolates were screened finally for Phosphate solubilization under saline condition(Figure:3).Only those isolates which gave maximum growth(fast growers) ,zone of phosphate solubilization were selected for further studies.Colony characteristics of isolates growing on $6 \% \mathrm{NaCl}$ concentration is shown in Table:2

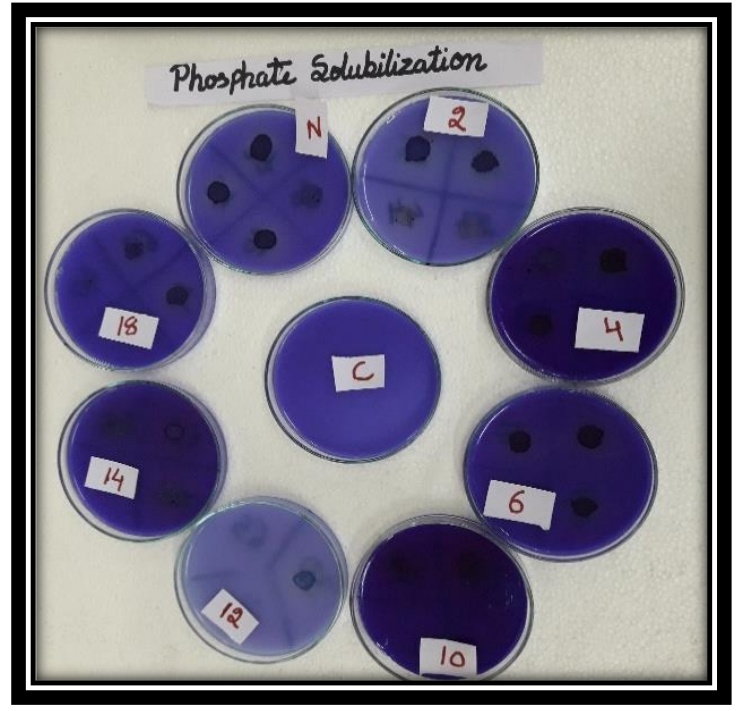

Figure:3 Isolates on Pikovskaya agar plates having $\mathrm{NaCl}$ concentration ranging from $2 \%$ to $18 \%$

Table: 2 Colony characteristics of isolates growing on $6 \% \mathrm{NaCl}$ concentration

\begin{tabular}{|c|c|c|c|c|}
\hline \multirow[t]{2}{*}{ Characteristics } & \multicolumn{4}{|c|}{ Type of colony on $\mathrm{NA}(6 \% \mathrm{NaCl})$} \\
\hline & 3 & 8 & 18 & 31 \\
\hline Size & small & medium & small & medium \\
\hline Shape & round & round & round & round \\
\hline Margin & even & even & even & even \\
\hline Surface & rough & smooth & rough & smooth \\
\hline
\end{tabular}




\begin{tabular}{|c|c|c|c|c|}
\hline $\begin{array}{l}\text { Elevation } \\
\text { Pigmentation }\end{array}$ & $\begin{array}{l}\text { flat } \\
\text { off white }\end{array}$ & $\begin{array}{l}\text { raised } \\
\text { pale white }\end{array}$ & $\begin{array}{l}\text { flat } \\
\text { off white }\end{array}$ & $\begin{array}{l}\text { raised } \\
\text { pale } \\
\text { yellow }\end{array}$ \\
\hline Consistency & dry & butyrous & dry & butyrous \\
\hline Opacity & opaque & opaque & opaque & opaque \\
\hline Gram's Reaction & positive & negative & positive & negative \\
\hline
\end{tabular}

\subsection{Qualitative Assay}

Results indicates that all the 4 four isolates showed zone of phosphate solubilization on solid Pikovskyaya's medium having $6 \% \mathrm{NaCl}$ concentration after $3 \mathrm{~d}$ of incubation at $30 \pm 2^{\circ}$ (Figure :4) The PSI of all four isolates ranging from 6 to 12 .

\subsection{Quantitative Assay}

Results indicates that all the 4 four isolates showed phosphate solubilization in liquid Pikovskyaya's medium having $6 \% \mathrm{NaCl}$ concentration after $14 \mathrm{~d}$ of incubation at $30 \pm 2^{\circ}$ (Figure: 5.) that was measured spectrophotometrically by Chlorostannous acid method.
Change in $\mathrm{pH}$ of the medium from 6.5 to a maximum of 3 was observed(Table:3). This change indicates that there is production of some organic acids that would contributed in inorganic phosphate to solubilize and make it available in soluble form. The phosphate solubilization in liquid medium was found to ranging from $9.66 \mu \mathrm{g} / \mathrm{ml}$ to $20 \mu \mathrm{g} / \mathrm{ml}$ under saline condition of $6 \% \mathrm{NaCl}$ concentration.

These all indicates that all the four isolates are capable of growing under saline conditions as well as can solubilize phosphate efficiently and can make available to plants for their better growth and production.

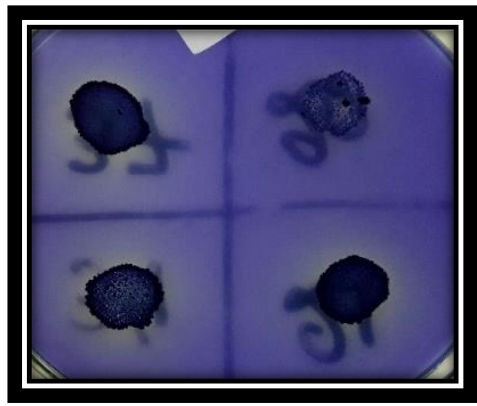

(a)

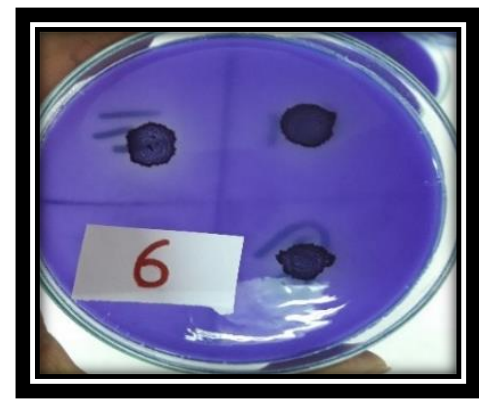

(b)

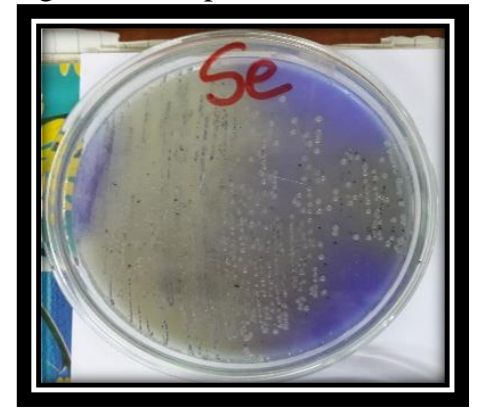

(c)

Figure :4(a) and (b)yellow zone of phosphate solubilization on Pikovskaya's agar plates having $6 \% \mathrm{NaCl}(\mathbf{c})$ Enrichment technique plate

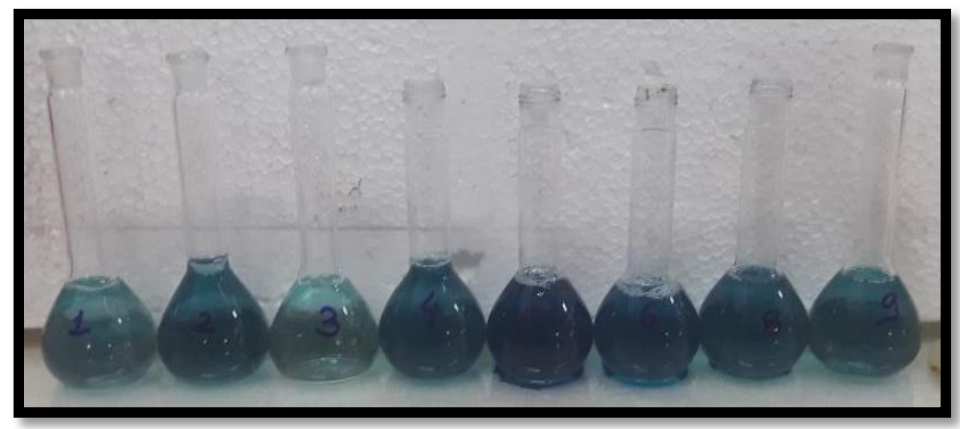

Figure: 5 Quantitative estimation of phosphorus solubilized by PSB

Table: 3 Change in $\mathrm{pH}$ of the medium and PSI of isolates

\begin{tabular}{lccc}
\hline Isolate No. & $\begin{array}{c}\mathbf{p H} \\
\mathbf{7}^{\text {th }} \mathbf{d}\end{array}$ & $\begin{array}{c}\mathbf{p H} \\
\mathbf{1 4}^{\text {th }} \mathbf{d}\end{array}$ & PSI \\
\hline 3 & 5.5 & 3.7 & 6 \\
\hline
\end{tabular}




\section{International Journal of Research in Advent Technology, Vol.7, No.5, May 2019 E-ISSN: 2321-9637 Available online at www.ijrat.org}

\begin{tabular}{llll}
\hline 8 & 5.2 & 3.0 & 10 \\
18 & 5.4 & 3.3 & 8 \\
31 & 5.0 & 3.3 & 12 \\
\hline
\end{tabular}

\section{CONCLUSION}

From this study it is concluded that isolates which gave maximum growth (fast growers) ,zone of phosphate solubilization growing on $6 \% \mathrm{NaCl}$ concentration indicates their tolerance towards salt stress. They can be used as bio fertilizers in saline areas for crop production. Halotolerant PSB will facilitate the development of saline-alkali soil-based agriculture .The PSI of all the studied isolates was in range of 6 to 12 which implicates that theses PSB can be used as a means of fixing the nutrient availability in the soil especially phosphorus.This will reduce the use of chemical PNK fertilizers for higher crop yield. Phosphorus is an important macronutrient that is essential for plant growth and development. They will involve in maintaining the phosphorus cycle. They can easy shows symbiotic association with plants roots.PSB function is in long duration, causing improvement in soil fertility.Using these isolates as bioinoculant will make salt affected area to support the cultivation of crops . They can maintain the natural habitat of soil. They are easy to apply without any additive agents. They are cost effective bio fertilizer and having low manufacturing cost. Hence,PSB can be considered as an ecofriendly approach towards sustainable agriculture path.

\section{ACKNOWLEDGEMENT}

I am thankful to my guide and Head of Department Prof. (Dr.) Meenu Saraf for always guiding me and to the teaching and non-teaching staff, to my lab colleagues and seniors for always supporting and helping in my work.

\section{REFERENCES}

[1] Aziz, Tariq, MUHAMMAD AAMER Rahmatullah, Muhammad Aamer Maqsood, I. Ahmad Tahir, and Cheema MA. "Phosphorus utilization by six Brassica cultivars (Brassica juncea L.) from tricalcium phosphate; a relatively insoluble $\mathrm{P}$ compound." Pak. J. Bot 38, no. 5 (2006): 15291538.

[2] Plaxton, William C., and M. Christian Carswell. "Metabolic aspects of the phosphate starvation response in plants." Plant responses to environmental stresses: from phytohormones to genome reorganization. Marcel Dekker, New York (1999): 349-372.
[3] Raghothama, K. G. "Phosphate acquisition." Annual review of plant biology 50, no. 1 (1999): 665-693.

[4] Yin, Zhongwei, Fachao Shi, Hongmei Jiang, Daniel P. Roberts, Sanfeng Chen, and Bingquan Fan. "Phosphate solubilization and promotion of maize growth by Penicillium oxalicum P4 and Aspergillus niger P85 in a calcareous soil." Canadian journal of microbiology 61, no. 12 (2015): 913-923.

[5] Amit, Sagervanshi, Kumari Priyanka, Nagee Anju, and Kumar Ashwani. "Isolation and characterization of phosphate solublizing bacteria from Anand agriculture soil." Advance Research in Pharmaceuticals and Biologicals 2, no. 3 (2012).

[6] Gaur, A. C. "Physiological functions of phosphate solubilizing micro-organisms." Phosphate solubilizing micro-organisms as biofertilizers. Omega Scientific Publishers, New Delhi (1990): 16-72.

[7] Khan, Mohammad Saghir, Ees Ahmad, Almas Zaidi, and Mohammad Oves. "Functional aspect of phosphate-solubilizing bacteria: importance in crop production." In Bacteria in agrobiology: Crop productivity, pp. 237-263. Springer, Berlin, Heidelberg, 2013.

[8] Ouahmane, Lahcen, Jean Thioulouse, Mohamed Hafidi, Yves Prin, Marc Ducousso, Antoine Galiana, Christian Plenchette, Marija Kisa, and Robin Duponnois. "Soil functional diversity and P solubilization from rock phosphate after inoculation with native or allochtonous arbuscular mycorrhizal fungi." Forest Ecology and Management 241, no. 1-3 (2007): 200-208.

[9] Ahuja, Amita, S. B. Ghosh, and S. F. D'souza. "Isolation of a starch utilizing, phosphate solubilizing fungus on buffered medium and its characterization." Bioresource technology 98, no. 17 (2007): 3408-3411.

[10] Sharma, Seema B., Riyaz Z. Sayyed, Mrugesh H. Trivedi, and Thivakaran A. Gobi. "Phosphate solubilizing microbes: sustainable approach for managing phosphorus deficiency in agricultural soils." SpringerPlus 2, no. 1 (2013): 587.

[11] Manzoor, M., M. Kaleem Abbasi, and Tariq Sultan. "Isolation of phosphate solubilizing bacteria from maize rhizosphere and their potential for rock phosphate solubilization-mineralization and plant growth promotion." Geomicrobiology journal 34, no. 1 (2017): 81-95. 
[12] Biswas, D. R., and G. Narayanasamy. "Rock phosphate enriched compost: an approach to improve low-grade Indian rock phosphate." Bioresource Technology 97, no. 18 (2006): 2243-2251.

[13] Xiao, Chunqiao, Ruan Chi, Xiao Pan, Feng Liu, and Jiawei He. "Rock phosphate solubilization by four yeast strains." Annals of microbiology 63, no. 1 (2013): 173-178.

[14] Bakhshandeh, Esmaeil, Hemmatollah Pirdashti, and Khadijeh Shahsavarpour Lendeh. "Phosphate and potassium-solubilizing bacteria effect on the growth of rice." Ecological Engineering 103 (2017): 164169.

[15] Hart, Murray R., Bert F. Quin, and M. Nguyen. "Phosphorus runoff from agricultural land and direct fertilizer effects." Journal of Environmental Quality 33, no. 6 (2004): 1954-1972.

[16] Premono, M. Edi, A. M. Moawad, and P. L. G. Vlek. Effect of phosphate-solubilizing Pseudomonas putida on the growth of maize and its survival in the rhizosphere. No. REP-12113. CIMMYT. 1996. 